cers and cavalry regiments followed : then came the su. No eve could bear more gorgeousness; no more gor- gone before-all the soldiers and sailors, the big limbed preme moment for which the many millions had been geousness could there be, unless princes are to elcthe waiting. Field Marshal Lord Wolselev, Commander-in- themselves in rainbows and the very sun. were seen the cream colored horses which were famous was at hand. Already carriages were rolling up, full throughout the elnpire drawing the carriage in which of the Queen's kindred, full of her children and chil-
sat the sovereign. T'he enthusiasm knew no bounds. \begin{tabular}{l|l} 
It could, perhaps, be described adequately by saying it there through an avenue of eager faces, through a \\
was an avalanche of sound. It was difficult to believe \\
storm of white, waving handkerchiefs, through roaring
\end{tabular} that seventy-eight eventful years had passed over the volleys of cheers, there was approaching a carriage
Queen's head. Her Majesty was seated opposite the drawn by eight cream colored horses. The roar surged Princess of Wales and the Princess Christian. The up the street, keeping pace with the eight horses. Prince of Wales, the Duke of Connaught and the Duke The carriage passed the barrier; it entered the churchiowed the royal standiard, grooms and equerries. Last the very steps of the cathedral, right; it drove up to ron of the Horse Guards. When the Queen's carriage $\quad$ the enthusiasm swelled to delirium. The sun, watery reached 'Temple Bar the Lord Mayor was waiting to re- until now, shone out suddenly, clear and dry, and sent a pearl sword of state. She spoke a few words in old lady, all in black, with a silver streak under he

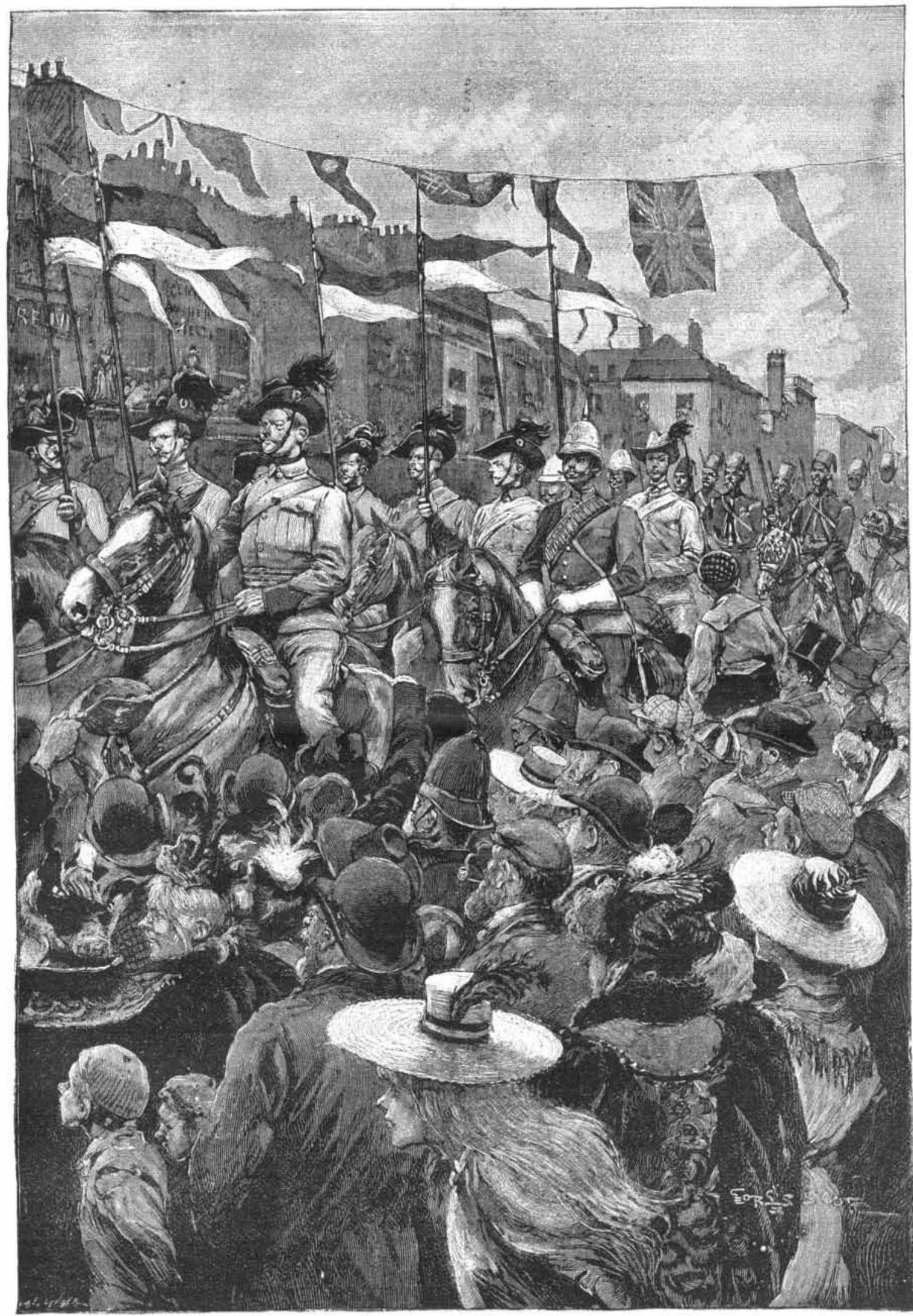

THE QUEEN'S JUBILEE-COLONIAL TROOP PASSING THROUGH WHITECHAPEL.

reply to the address of the Lord Mayor and the proces- black bonnet, and with a simple white sunshade, sion moved on to St. Paul's.
As the Queen approached St. Paul's Cathedral the
tight, as if she was trying not to cry. But that old (an was the Queen, ous train of clericals, emerged from the west front and want to look at the glittering uniforms now, nor yet at Her Majesty. Immediately, as the Queen's carriage was yet at the stately princes, though by now all these wer drawn up, the choir intoned the "Te Deum," after which the Bishop of London offered a prayer. The Archbishop of Canterbury then pronounced the bene-
diction, after which the choir sang the Hundredth Whe the cirlish Queen had been figure in the mide of these shining cavaliers, this anointed in Westminster Abbey, sixty years before. great army, this roaring multitude, but it was also 'The ceremonies at St. Paul's were so in ears before. we cannot refrain from giving Mr. G. W. Steevers' pen picture of the event which he gave in the Daily Mail.

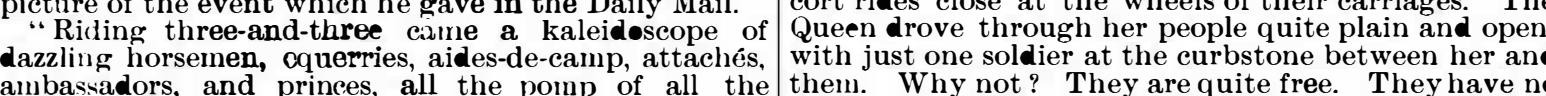
. Why not? They are quite free. They have no $\begin{array}{ll}\text { purple and crold, emerald and gold, white and gold- } & \text { Was it not all for her-gala trappings of the streets, } \\ \text { always a chimnging tumult of colors that seemed to list } & \text { men, horses, guns, and the living walls of Britis', men }\end{array}$ and gleam with a light of their own. It was enough. and women? For the Queen sumned up all that had colonials, and the strange men from unheard of islands
over sea. all stood for. We knew as we had never known before what the Queen stands for. The empire had come The mother of the empire had come to do homage to one Being more majestic than she.

"There were the archbishops, bishops and deans in
gold and crimson caps and white, orange and gold embroidered vestments waiting on the steps. There, could see all her ministers and great men, a strange
cound in the pillars and scaffoldings, you plimpse of miniature faces as in some carefully labored picture, where each face stands for an honored name.
"All stood, and the choir sang the "Te Deum.' Next rose up a melodious voice intoning prayers. 'The the company outside the cathedral and the whole company in the stands, at the windows, on the housetops, and away down the street, all standing, all uncovered, began to sing the One Hundredth Psalm, "The Queen's lips were tight, and her eyes, perhaps the Queen!" and the dean, pious man, was wildiy the Queen! and the dean, pious man, was withiy and roofs were ringing as if they must come down. drowned in soun

The Queen looked up and smiled, and the Queen's smile was the end and crown of it all, a smile that broke down the sad mouth, a smile that seemed hal motherly." The colonials fell in behind the royal procession after leaving St. Paul's. A brief stoppage was made at the Mansion House by the Lord Mayor's wife, who presented a bouquet to the Queen, and here Her Majesty
dispensed with the attendance of the Lord Mayor, who had accompanied her from 'Temple Bar. 'I'lue procesBridge. and thence along the streets on the southern side of the 'Thames. turn of Her Majesty to the palace, she lay down for an hour, and spent the rest of the afternoon in the garden. She bore the fatigue exceedingly well. The enthusiasm of the British people for several days was unbounded, and the splendid display of sea powerhead, was the other crowning feature of this memorable

Our engravings, for which we are indebted to sor before the departure of the Queen, and the colo nial soldiers in the procession, and the procession pass.

INCREASE OF THE DRYING POWER OF OILS.

THE principal factors which increase the power of fixing oxygen of a siccative oil such as linseed are, first, which has elapsed since its extraction; thirdly the conwhich has elapsed since its extraction: thirdly, the con-
ditions under which it has been kept; fourthly, heat; fifthly, the addition of certain substances. has been extracted by the press, it contains water and impurities, and it is evident that in order to have an elastic and even mass, it is an advantage to extract these substances. This is done either naturally, allow-
ing the clarification to proceed by simple deposit, or by This last means, which generally consists of treating the oil with sulphuric acid, frees it from substances which do not play any part in its drying qualities, as they do not fix oxygen. As a matter of fact, in a comparative test by exposure to the air of a recently pressed oil and the same oil treated with sulphuric
acid, then freed by washing from all trace of the acid, it is seen that in the second case the oil absorbs a greater quantity of oxygen. Moreov $ə r$, it is evident that
the final product will be the whiter, as the oil, to begin with, is less colored, which suggests the necessity of the bleaching operation. 2. Age of the Oil.-Oil preserved from the action of
the air absorbs oxygen the better the older it is. It is thought that it is due to the formation of new compounds in the oil. Dr. Fahrion believes that the non-
saturated fatty acids enter into combinations among saturated fatty acids enter into combinations among themselves to form new and complex bodies.
3. Method of Preservation of the Oil.-Outside the question of age, if the oil has been kept in such condiready absorbed a certain quantity of oxygen. Experience shows that even if to begin with the oil only
slowly absorbs oxygen. once this absorption has begun, it proceeds much more rapidly. In any given oil, therefore, the absorption of the oxygen will take place much more rapidly when it has been exposed to the air.
4. Action of Heat.-The temperature at which an 4. Action of Heat.- The temperature at which an oil is exposed to the air has influence upon its drying than at a temperature of from $15^{\circ}$ to $18^{\circ} \mathrm{C}$. Moreover if crude linseed oil and the same oil which has first been submitted to the action of the heat are exposed
to the air under the same conditions of temperature, a to the air under the same conditions of temperature, a difference in their drying powers will be found. If,
for instance, linseed oil is heated for three hours, so that it only isengages a few gaseous bubbles from time to time, the oil becomes much more siccative, as Chevdry. Dr. Fahrion explains this by saying that, under such conditions, boiling in a deep vessel to which little of the oxygen of the air can gain access, the conbination of the non-saturated fatty acids among them-
selves is accelerated, and complex products are formed capable of absorbing oxygen more rapidly. the same conditions, proved, on the other oil nnder the oil heated for five hours is at the end of this time
less siccative than the oil heated for three homs only. less siceative than the oil heated for three homis only:
It is probable that under the influence of this pro: 
longed heat a part of the glycerine is destroyed, as a
certain acrid sinell indicates, and the linoleic acid is certain licrid sinell indicates, and the linoleic acid is
set at lickly and in that linoleic acid dries
less quickly than linolein. It is probable for the same reason that Mulder has found that linseed oil heated
only to from $70^{\circ}$ to $100^{\circ} \mathrm{C}$. dries less well than crude il. We can sum up, therefore, as follows: First, that oil; secondly, that exposed to the same temperature submitted to the action of heat, with this reserve, that the action of heat has been such that the oil has not commenced to decompose, with the result that a cer-
tain quantity of linoleic acid has been set at liberty. 5. The Addition of Certain Substances. - Long expe-
rience has shown that the addition of certain subrience has shown that the as white lead, litharge, oxide of manganese, etc., assists the drying of a siccative oil. In cercold oil, in other cases heat is used in making the mix Let us first consider the plumbic compounds which have been employed for a long time as driers. The commonest process consists in heating the oil with
these plumbic compounds, and the increase of drying of linoleate of lead, at the same time that linoleic acid is liberated by the heat, and sometimes to the oxidation out as a proof of this that at the end of the operation there is a deposit of a certain quantity of metallic lead. This double explanation does not seem exact, for the
following reasons : In the first place, experience teaches following reasons: In the first place, experience teaches power, since the product quickly becomes brittle and friaiek. than linoxine. Nevertheless, it is indisputable
that an oil heated with oxide of lead has a drying power greater than a crude oil, or oil cooked without
the addition of the oxide. It may be asked, therefore if it is not owing to the oxygen of the oxide of lead that the drying power is augmented. If it is remem-
bered that a linseed oil of good quality, exposed to
the air, absorbs 16 to 18 per cent. of its weight on turning into a solid and perfectly dry substance, and if, on the other hands-we reflect that in practice the quantity of oxide of lead used is not more than 3 to 8 per cent
of the oil, it will be seen that the oxygen that the ox-
ide of lead could furnish is less than 1 per cent. of the ide of lead could furnish is less than 1 per cent. of the weight of the oil, whereas from 16 to 18 per cent. are more than a secondary part from the point of view of of lead does not give up any of its oxygen, since it enters directly into combination to form a plumbic
soap. Nevertheless the presence of a certain quantity of metallic lead at the end of the operation proves that a corresponding quantity of oxygen has been at libhave seen in studying the effect of oxygen on crude oil, the drying proceeds more rapidly after the oxida-
tion of the oil has reached a certain degree. In any case, this reaction seems to be a secondary one, in view of the notable increase of the drying power. The same objections and the same explanation might be arying power by the use of manganic compounds.

given based upon a very important observation made spread on a sheet of lead entirely freed from all trace of oxide, the drying power of the oil notably increased. any oxygen, except, that which is furnished normally by the air. The augmentation of the drying power is
due really to nothing else than the presence of the metal. This experiment may be carried further. If a metal. This experiment may be carried further. If
crude siccative oil is shaken up in a bottle, with very porous lead. obtained by the precipitation of a salt of necessity of any elevation of temperature the siccative oil has a much greater drying power than before this oil has a much greater drying power than before this
treatment, and in this case it is certain that the oil has
not teen furnished with any oxygen. The only certain not been furnished with any oxygen. The only certain ted lead the oil contains a small quantity of the metal, the drying power is due uniquely to the presence of The same experiment cannot be made directly with the manganic compounds, but indirectly the oil can be placed in the same conditions with regard to manganese. To do this it is merely necessary to stir up the
oil treated with the precipitated lead with a salt of manganese, the sulphate, for instance, which by double the same time manganese as a substitute for the lead. thus " manganesated" has a very great drying power, with a manganic compound. It is by experimenting upon this manganesated oil thus prepared that it is
possible to find an explanation of the augmentation of possible to find an explanation of the augmentation of in contact with the air, it is seen to take a brown tint superior degree of oxidation, by taking oxygen from the air. But as the oil becomes more viscous the brown tint is seen to disappear; finally this coloration disappears completely, the oxygen of the peroxide of manfinally a solid mass without color is obtained.
'This brown coloration, followed by a complete loss of 'This brown coloration, followed by a complete loss of
color, shows that the oxide of manganese has served as
an intermediary, itself oxidizing easily by contact with the oxygen of the air, and then giving up this oxygen to the oil. The action obtained with oxide of lead is very proba-
bly similar to this, but with a smaller degree of energy In an oil to which litharge or manganese has been adcled, the lead and the manganese play a part of in-
termediaries, robbing the air of its oxygen to give it termediaries, robbing the air of its oxygen to give it
up in a continuous manner to the oil, which is thus oxidized more rapidy than it would be without these
in termediaries.
It was natural to try if other metals were capable of
funnels starts the holder. $\mathbf{K}$ is the gas supply pipe
from the gasometer. V is a safety valve, as a precauplaying the same part as lead and manganese. The
simplest way of experimenting in this direction is to
tronerator pots are closed by the cocks, $R \mathbf{R}^{1}$, when the simplest way of experimenting in this direction is to
talie an oil to which litharge has been added and stir pots are closed by the cocks, $\mathbf{R} \mathbf{R}^{1}$, when the
apparatus is not in use there would be a chance of these cocks being left shut through a forget when
they should be open, so each pot is fitted with a water siphon, the seals of which would naturally be broken
by any excess of gas in the generators. by any excess of gas in the generators.
Only one generator is used at a time under ordinary circumstances, and as soon as the charge in one is ex-
hausted the other is started, so that the gas supply car be kept up indefinitely. The smallest apparatus made contains about one pound of calcium earbide in each generator, or one
kilogramme in all. This charge is good for ten hours oil takes from thirty to thirty-six hours to finally, the oils obtained by substituting nickel, chrome, etc. for the lead are not completely dry until point to note is that a manganesated oil got by substi-
tuting manganese for the lead of an oil prepared with tuting manganese for the lead of an oil prepared with sated directly.

In practice, in addition to the oxides of lead and of their choice seems as if it should be subordinated to their degree of solubility in the oil and the manner than the acetate of lead and the borate of mane other have been retained, and the explanation of this is easy. It is that these two salts submitted to the heat decom-
pose and give finally either the oxide of lead and very the case of the acetate of lead, it is known that this salt melts in its water of erystallization at about 75 and a little acid, giving a sesqui-basic acetate, which is acid and acetone are freed, and as a residue very finely
divided lead is obtained, of which we have already seen the important role as a drier.

ith a case of borate of manganese we have to deal The affinity of the boric acid for the oxide of mangaThe affinity of the boric acid for the oxide of manga-
latter is set at liberty. The use of this salt is, therefore, simply an advantageous way of introducing the As of manganese

As experience has shown that metallic lead in a very
porous state augments the drying power of the oil, it was interesting to study the action on the oil of other however, with precipitated copper and tin, it was found crease. This result was to be foreseen, for Chevreul
had shown that linseed oil spread on a well cleaned sheet of lead dried much more rapidly than that spread metals the drying power was not much more rapid than ter--Vernis et Huiles Siccatives ; from the Western Painter.

RECENT IMPROVEMENTS IN ACETYLENE GAS GENERATING APPARATUS.

THE means for producing acetylene gas are constantly being improved in Paris. Low pressures alone
are favorably considered. A very important indusinventurs are not idle in devising apparatus for giving

The superproduction of gas after the cessation of
consumption has met with the most attention in recent appliances. This inconvenience was combated in glass rings divid ing the carbide into parcels, and so, in some measure, preventing a too rapid attack upon the
whole of the chemical. In the newest machines the water is fed to the carbide automatically by the moveelevation of the nolder, the less the quantity of water allowed to the carbide. As an example of this type of Rue de la Victoire, Paris, is one of the simplest for the purpose of illustration. $G \mathrm{G}$ are two cast iron pots,
readily slid out from under their covers for the pur-
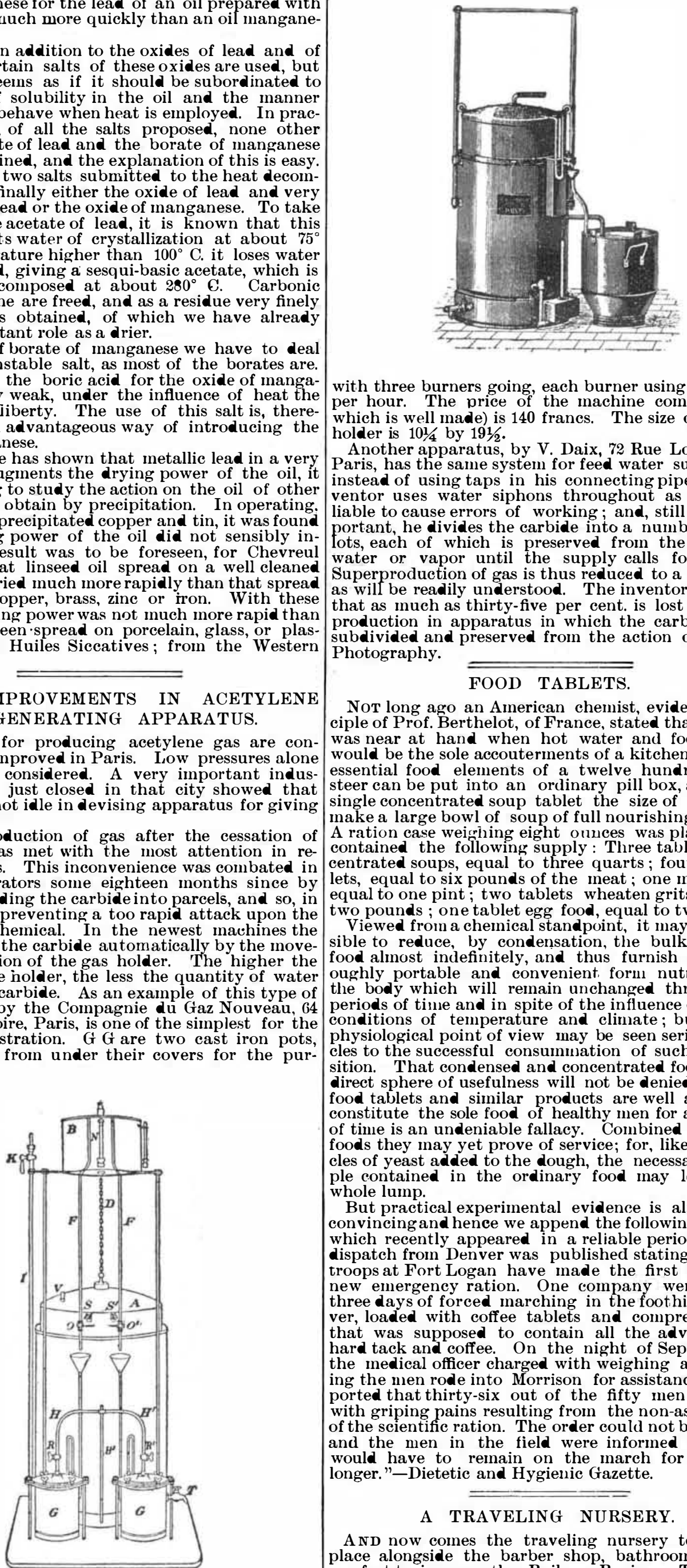

with three burners going, each burner using ten liters which is well made) is 140 francs. The size of the gas holder is $101 / 4$ by $191 / 2$. Another apparatus, by V. Daix, 72 Rue Louis Blanc, instead of using taps in his connecting pipes, this in-
ventor uses water siphons throughout as being less ventor uses water siphons throughout as being less
liable to cause errors of working; and, still more imliable to cause errors of working; and, still more im-
portant, he divides the carbide into a number of small ots, each of which is preserved from the action of
water or. vapor until the supply calls for its use. Superproduction of gas is thus reduced to a minimurn, that as readily understood. The inventor estimates production in thirty-five per cent. is lost by super production in apparatus in which the carbide is not
subdivided and preserved from the action of vapor.-
Photography.

\section{FOOD TABLETS}

Not long ago an American chemist, evidently a dis-
ciple of Prof. Berthelot, of France, stated that the time ciple of Prof. Berthelot, of France, stated that the time essential food elements of a twelve hundred pound single concentrated soup tablet the size of a pea will make a large bowl of soup of full nourishing strength. A ration case weiching eight ounces was planned. It
contained the following supply : Three tablets of conlets, equal to six pounds of the meat; ; one milk tablet, two pounds; one tablet egg food, equal to twelve eggs. ible to reduce, by condensation, the bulk of possible to reduce, by condensation, the bulk of man's oughly portable and convenient form nutriment for
the body which will remain unchanged through long periods of time and in spite of the influence of varying physiological point of view may be seen serious obstasition. That condensed and concentrated foods have a
direct sphere of usefulness will not be denied, but that
food tablets and similar products are well adapted to food tablets and similar products are well adapted to of time is an undeniable fallacy. Combined with fresh foods they may yet prove of service; for, like the partiple contained in the ordinary food may leaven the But practical experimental evidence is always most convincing and hence we append the following dispatch which recently appeared in a reliable periodical: "A dispatch from Denver was published stating that the
troops at Fort Logan have made the first test of the new emergency ration. One company went out for ver, loaded with coffee tablets and compressed soup that was supposed to contain all the advantages of hard tack and coffee. On the night of September 11, the medical officer charged with weighing and watching the men rode into Morrison for assistance. He rewith griping pains resulting from the non-assimilation of the scientific ration. The order could not be revoked, and the men in the field were informed that they longer."-Dietetic and Hygienic Gazette.

A TRAVEling NURSERY

AND now comes the traveling nursery to take its place alongside the barber shop, bathroom, etc., on ing nursery is to take up about the same amount of space as the private stateroom of the ordinary sleeping
car. There will be a saving of a space of several feet,

pose of refilling. $\mathrm{H} \mathrm{H}^{1} \mathrm{H}^{2}$ connect the generators to the gas holder, A, to the top of which is attached a reservoir, B, so that the water therein is opened to or
cut off from the two supply pipes, F F, feeding the cut off from the two supply pipes, F F, feeding the
carbide holders. The supply is commenced automaticarbide holders. The supply is commenced automati-
eally by means of two spring catches, $\mathrm{S} S$, attached to however, as the wide seats on the sides of the state-
room below the berths are not needed in the nursery, being replaced by ottomans and tiny easy chairs scatterever the floor. In this way any danger from sudden starts or sharp curves is obviated. As a further prohe nursery are heavily padded and the floor thickly
the arpeted, so that bumps and bruises will be altogether
voided. At each end of the compartment, and firmly avoided. At each end of the compartment, and firmly nay lie and watch the games of the older ones. Each may lie and watch the games of the older ones. Each
car containing the nursery attachment will carry a mia- 